\title{
EL DEBER DE SEGURIDAD
}

\author{
María Cristina Gajardo Harboe* \\ Universidad de Chile
}

\begin{abstract}
RESUMEN: Este trabajo trata acerca de la naturaleza del deber de seguridad en las relaciones laborales desde sus fuentes constitucionales y legales determinando su naturaleza y alcances.
\end{abstract}

Palabras clave: Derecho del trabajo - relaciones laborales - deber de seguridad.

ABSTRACT: This work deals with the nature of the security duty in labor relations from their constitutional and legal sources, determining its nature and scope.

Key words: Labor law - labor relations - security duty.

Dentro del contenido no patrimonial del contrato de trabajo se encuentra este importante deber, traducido en la obligación del empleador de crear y mantener condiciones seguras en el ambiente y en las instalaciones de los recintos de trabajo que están bajo su dirección, lo que no excluye importantes responsabilidades para los trabajadores y para el Estado.

Desarrollarlo en clave laboral permite apreciar este deber en función de las garantías fundamentales en que incide, esto es, el derecho a la vida y la integridad física y psíquica de los trabajadores. Hoy el tema parece estar dominado por los civilistas, a propósito de las implicancias en materia de responsabilidad del empleador en la reparación de los daños, visión que no permite delinear este deber en función del objetivo perseguido, que no es otra cosa que la protección del trabajador en su lugar de trabajo, a través del desarrollo de un "derecho de la prevención de riesgos" que Chile está lejos de tener.

La terminología asociada a este deber es variable: "seguridad" y "salud" en el trabajo con referencia a la prevención de riesgos en sus aspectos técnicos y a la medicina del trabajo; "higiene" y "seguridad industrial" en antiguos textos reglamentarios. Detrás de estos conceptos está presente esta obligación de seguridad, a la que dedicaremos el presente estudio.

\section{LOS INSTRUMENTOS DE LA OIT EN SEGURIDAD Y SALUD EN EL TRABAJO}

En el documento sobre su Constitución, la OIT señala que el organismo deberá fomentar programas que permitan proteger adecuadamente la vida y la salud de los trabajadores en todas las ocupaciones ${ }^{2}$, cuestión que como se advertirá más adelante no atañe sólo a los empleadores sino a la propia OIT, a los Estados Miembros y a los trabajadores.

El instrumento más importante de la OIT, atendido el ámbito de materias que considera, es el Convenio N 155 de 1981, sobre "La Seguridad y la Salud de los Trabajadores"3. Es un conjunto

\footnotetext{
* Abogada. Magíster en Derecho. Directora del Departamento de Derecho del Trabajo y la Seguridad Social, Facultad de Derecho de la Universidad de Chile.

DS 655 de 1941, Ministerio del Trabajo, sobre Reglamento de Higiene y Seguridad Industriales.

Constitución de la OIT, 1919, Apartado III, letra g) de Anexo.

No se encuentra ratificado por Chile.
} 
María Cristina Gajardo Harboe / El Deber de Seguridad

de normas aplicables a todas las ramas de la economía y establece deberes para los Estados, dentro de los que se cuenta el establecimiento de una "política nacional sobre seguridad y salud en el trabajo", que tendrá por objeto precisar las funciones y responsabilidades respectivas, en materia de seguridad y salud de los trabajadores y medio ambiente de trabajo, de las autoridades públicas, los empleadores, los trabajadores y otras personas interesadas, teniendo en cuenta el carácter complementario de tales responsabilidades, así como las condiciones y la práctica nacionales (Art. 4).

Enseguida, el Convenio $\mathrm{N}^{\circ} 155$ explicita la necesidad de controlar la aplicación de las leyes y de los reglamentos relativos a la seguridad, la higiene y el medio ambiente de trabajo, a través de un sistema de inspección apropiado y suficiente (Art. 9). Exige también medidas conformes a la legislación y práctica nacionales a fin de velar por que las personas que diseñan, fabrican, importan, suministran o ceden a cualquier título maquinaria, equipos o sustancias para uso profesional: (a) se aseguren, en la medida en que sea razonable y factible, de que la maquinaria, los equipos o las sustancias en cuestión no impliquen ningún peligro para la seguridad y la salud de las personas que hagan uso correcto de ellos; (b) faciliten información sobre la instalación y utilización correctas de la maquinaria y los equipos y sobre el uso correcto de substancias, sobre los riesgos que presentan las máquinas y los materiales y sobre las características peligrosas de las sustancias químicas, de los agentes o de los productos físicos o biológicos, así como instrucciones acerca de la manera de prevenir los riesgos conocidos (Art. 12); y la adopción de medidas a fin de promover, de manera conforme a las condiciones y a la práctica nacionales, la inclusión de las cuestiones de seguridad, higiene y medio ambiente de trabajo en todos los niveles de enseñanza y de formación, incluidos los de la enseñanza superior técnica, médica y profesional, con objeto de satisfacer las necesidades de formación de todos los trabajadores (Art. 14).

Recién en su parte IV el Convenio $\mathrm{N}^{\circ} 155$ establece que deberá exigirse a los empleadores que, en la medida en que sea razonable y factible, garanticen que los lugares de trabajo, la maquinaria, el equipo y las operaciones y procesos "que estén bajo su control" son seguros y no entrañan riesgo alguno para la seguridad y la salud de los trabajadores; que deberá exigirse a los empleadores que, en la medida en que sea razonable y factible, garanticen que los agentes y las sustancias químicos, físicos y biológicos "que estén bajo su control" no entrañan riesgos para la salud cuando se toman medidas de protección adecuadas; que cuando sea necesario, los empleadores deberán suministrar ropas y equipos de protección apropiados a fin de prevenir, en la medida en que sea razonable y factible, los riesgos de accidentes o de efectos perjudiciales para la salud (Art. 16).

Y en el ámbito de la cooperación entre los intervinientes en el proceso productivo, el convenio establece que deberán adoptarse disposiciones a nivel de empresa en virtud de las cuales: (a) los trabajadores, al llevar a cabo su trabajo, cooperen al cumplimiento de las obligaciones que incumben al empleador; (b) los representantes de los trabajadores en la empresa cooperen con el empleador en el ámbito de la seguridad e higiene del trabajo, entre otras obligaciones (Art. 19).

Enseguida se encuentra el Convenio 187 de 2006, sobre "Marco Promocional de la Seguridad y Salud en el Trabajo". Es objetivo de este convenio promover la mejora continua de la seguridad y salud en el trabajo con el fin de prevenir las lesiones, enfermedades y muertes ocasionadas por el trabajo mediante el desarrollo de una "política nacional, un sistema nacional de seguridad y salud en el trabajo, y un programa y una cultura nacionales", en consulta con las organizaciones más representativas de empleadores y de trabajadores (Art. 2).

En cuanto a los ámbitos de acción de este Convenio 187 de la OIT, destacan:

Ratificado por Chile a través del DS No 72, Publicado en el Diario Oficial de 19 de agosto de 2011, del Ministerio de Relaciones Exteriores. 
- Política nacional: ésta debe ser desarrollada con representatividad de las organizaciones pertinentes.

- Sistema nacional: Se debe desarrollar una infraestructura legal e institucional para la aplicación de la política y los programas nacionales.

- Programa nacional: Debe incluir objetivos, metas, plazos, prioridades, y medios de acción y evaluación.

- Cultura nacional de prevención: Esta debe estar basada en el derecho a un medio ambiente de trabajo seguro y saludable, que se respeta a todos los niveles; en la que se participa activamente, con derechos, deberes y responsabilidades bien definidas, concediendo a la prevención la máxima prioridad.

Como puede apreciarse, de los dos Convenios con carácter general que la OIT tiene en materia de seguridad y salud en el trabajo, Chile ha ratificado el menos exigente, esto es, el Convenio $\mathrm{N}^{\circ} 187$, con un moderado grado de implementación.

En efecto, habiéndose constituido una comisión de encuesta ${ }^{5}$ para la revisión del marco legal que regía la protección contra los accidentes del trabajo y las enfermedades profesionales, la que emitió importantes lineamientos en su informe de fecha noviembre de 2010, al año 2014 contamos con los siguientes nuevos instrumentos legales:

- DS N¹9 de 2011, del Ministerio del Trabajo y Previsión Social, que crea y regula el funcionamiento de un Consejo Consultivo para la Seguridad y Salud en el Trabajo.

DS N²0 de 2011, del Ministerio del Trabajo y Previsión Social, que establece un Comité de Ministros para la Seguridad y Salud en el Trabajo.

Ley N²0.691 -Diario Oficial de 14 de diciembre de 2013-, sobre nuevas facultades para la Superintendencia de Seguridad Social.

Por otra parte, de la estructura del Convenio 155 brevemente anotada se colige con mucha claridad que la prevención de riesgos en el trabajo no es una materia que sea de la exclusiva responsabilidad de las entidades empleadoras, a quienes sin duda les cabe un rol importante; prueba de ello es el uso de las expresiones "que estén bajo su control" que utiliza el Artículo 16 respecto de las obligaciones de seguridad de las entidades empleadoras. Con todo, también el Estado y los propios trabajadores tienen deberes relevantes en esta tarea de prevención.

Nos parece que esta es la mirada correcta, la de la prevención de riesgos en el trabajo como una tarea de toda la sociedad, en tanto de lo que se trata es de proteger un derecho público subjetivo garantizado a todos los ciudadanos en el Art. $19 \mathrm{~N}^{\circ} 1$ de la Constitución Política de la República: el Derecho a la Vida y la Integridad Física y Psíquica del trabajador.

En consecuencia, sostenemos que la protección de la seguridad y salud en el trabajo, como garantía del derecho fundamental a la vida y salud del trabajador, no puede quedar entregada sólo a la autonomía privada de las partes en el contrato de trabajo, pues toca también al Estado promoverla y garantizarla. En esta línea resulta fundamental la ratificación por Chile del Convenio 155 , pues es el que establece el marco conceptual necesario para esta protección integral, del que el Convenio 187 sólo es instrumental. 


\section{LA SEGURIDAD Y SALUD EN EL TRABAJO EN EL MODELO CONSTITUCIONAL CHILENO}

Toca al Estado y a toda la comunidad -entre la que se encuentra el empleador- velar por el derecho a la vida y a la integridad física y psíquica del trabajador. Esto por así disponerlo nuestra Constitución Política de la República, al consagrar en el Artículo 19 que "La Constitución asegura a todas las personas: $\mathrm{N}^{\circ} 1$ el derecho a la vida y a la integridad física y psíquica de la persona”.

En estricta relación con la consagración de esta garantía fundamental, la Constitución en el Artículo 1, inciso $4^{\circ}$, sobre Bases de la Institucionalidad, dice que:

"el Estado está al servicio de la persona humana y su finalidad es promover el bien común, para lo cual debe contribuir a crear las condiciones sociales que permitan a todos y a cada uno de los integrantes de la comunidad nacional su mayor realización espiritual y material posible, con pleno respeto a los derechos y garantías que esta constitución establece"(inciso tercero), agregando que "es deber del Estado dar protección a la población y a la familia".

Agrega el Artículo 5, inciso $3^{\circ}$ que "es deber de los órganos del Estado respetar y promover tales derechos - esenciales que emanan de la naturaleza humana-, "garantizados por esta Constitución, así como por los tratados internacionales ratificados por Chile y que se encuentren vigentes".

Se incorpora a esta estructura normativa la ciudadanía en la empresa consagrada en el Artículo $5^{\circ}$ del Código del Trabajo, al establecer que "El ejercicio de las facultades que la ley le reconoce al empleador, tiene como límite el respeto a las garantías constitucionales de los trabajadores, en especial cuando pudieran afectar la intimidad, la vida privada o la honra de estos". Sobre esta norma, sabemos por la historia de la ley ${ }^{6}$ que la obligación del empleador de respetar las garantías fundamentales no se agota en las que acá se indican a título ilustrativo, lo que se hizo en razón de ser las garantías más frecuentemente vulneradas a la fecha de dicha iniciativa legislativa, de manera que se incorporan dentro del concepto de ciudadanía en la empresa todas las garantías fundamentales de que goza un ciudadano en Chile, y por ende está comprendido el derecho a la vida, a la integridad física y psíquica del trabajador.

Desde un punto de vista del Derecho de la Seguridad Social y siguiendo a Alejandro Silva Bascuñán, debemos tener también en cuenta su consagración como derecho fundamental en el N¹8 del Artículo 19 de la Constitución Política de la República. Este derecho es de naturaleza social y se funda en los principios de dignidad, igualdad y solidaridad, siendo su titular la persona humana, la cual puede exigir su cumplimiento a la sociedad en su conjunto ${ }^{7}$, representada en primer lugar por el Estado, a fin de que establezca las condiciones necesarias para su debido respeto y ejercicio. La seguridad social se ocupa de las contingencias que derivan de la vejez, enfermedad, accidentes del trabajo, viudez, orfandad, maternidad, invalidez, desempleo y cargas familiares, siendo deber del derecho y en definitiva del Estado que, en caso de acaecer alguno de estos estados de necesidad, se otorguen las prestaciones que sean necesarias para que la persona siga desarrollando su existencia de un modo digno. Corresponde entonces al conjunto de la socie-

www.bcn.cl, Historia de la Ley $\mathrm{N}^{\circ} 19.759$, pp. 83.

Lo que es aplicación de la Teoría del Riesgo Social que inspira la Ley N¹6.744 de 1968, sobre Seguro Social contra Riesgos de Accidentes del Trabajo y Enfermedades Profesionales. 
dad dar protección a todas las personas, para garantizar que, durante los estados de necesidad que se han descrito, se les asegure una digna subsistencia, como consecuencia de que la Constitución reconoce el derecho a la vida y a la integridad física y psíquica ${ }^{8}$.

Hasta aquí el modelo pareciera no tener mayores inconvenientes, puesto que en Chile hay un reconocimiento explícito en torno al derecho fundamental a la vida y a la salud de los ciudadanos y de los trabajadores en el ámbito de una relación laboral; en cuanto tal no sólo es deber del empleador, sino que también del Estado y de toda la sociedad hacerse cargo de su protección y también de su promoción, por incidir en otro derecho fundamental como es el derecho a la seguridad social.

El problema en nuestro entendimiento se encuentra en las "garantías" de los derechos fundamentales que se vinculan con el deber de seguridad, que vienen a ser los instrumentos jurídicos que dan eficacia y defensa a dichos derechos. Con frecuencia, como anota Mario Verdugo, los autores nacionales en sus textos asocian a las garantías sólo con las acciones constitucionales -amparo y protección principalmente- pero el tema es bastante más complejo. Distingue entre garantías generales, judiciales y específicas; dentro de las generales sitúa aquella garantía de la esencia de los derechos que contempla el Artículo 19 N² 26 de la Constitución Política de la República9 . Estimamos que también dentro de las garantías generales a los efectos de los derechos fundamentales que venimos refiriendo, ha de estar el establecimiento de un marco regulatorio preciso y determinado para asegurar su protección real, pues de otra forma no es posible una tutela efectiva en función de las materias en que incide.

Así las cosas, no es posible admitir que la tutela de garantías fundamentales tan relevantes como la vida y la salud de los trabajadores y el derecho a la seguridad social se agote, como ocurre hoy, con las reparaciones indemnizatorias del seguro social de la Ley $\mathrm{N}^{\circ} 16.744$ junto con las contempladas en el Derecho Civil. Hace falta más, se necesita desarrollar una efectiva cultura que evite los riesgos laborales, acompañada de verdadero derecho de la prevención de riesgos.

Existe un deber del Estado en orden a mantener una conducta activa -que a estos efectos no puede quedar comprendida dentro de su rol subsidiario- para diseñar políticas globales acordes con una nueva cultura de protección de la seguridad y salud en el trabajo, destinar recursos para su implementación, tener una institucionalidad creada para el seguimiento de sus resultados y dentro de ella un buen sistema de fiscalización a los recintos de trabajo. En este deber del Estado se comprende el proporcionar un marco regulatorio adecuado tanto a nivel legal como reglamentario que sea acorde con los derechos fundamentales que se busca proteger, tarea que no puede eludirse bajo el pretexto de existir normas que en nuestro ordenamiento atribuyan deberes de seguridad al empleador.

No sugerimos minimizar el deber de seguridad del empleador, sino de entenderlo dentro del contexto de los bienes jurídicos que protege, los que no pueden estar garantizados solo por la cuantía de las indemnizaciones que tan frecuentemente se obtienen en sede judicial por el ejercicio de acciones por responsabilidad civil del empleador, ya que de lo que se trata es de evitar los riesgos en el trabajo, que no se produzcan accidentes del trabajo ni enfermedades profesionales y en definitiva de respetar en la mejor forma posible la vida humana.

\footnotetext{
8 Silva Bascuñán, Alejandro. Tratado de Derecho Constitucional. Tomo XIII. Santiago, Chile: Editorial Jurídica de Chile, 2010, pp. 382-383.

Verdugo Marinkoovic, Mario. “Acerca de los Derechos Fundamentales y sus Garantías”, en: Derechos Fundamentales. Santiago, Chile: Editorial Jurídica de Chile, 2012, pp. 401-404.
} 


\section{DELINEAMIENTO DEL DEBER DE SEGURIDAD DEL EMPLEADOR}

\subsection{ES CONTRAPARTIDA AL PODER DE DIRECCIÓN DEL EMPLEADOR}

Se reconoce al empleador el derecho a dirigir y organizar el trabajo en sus aspectos económicos y técnicos, desde que es quien asume los riesgos del emprendimiento que significa la actividad laborativa. Este reconocimiento tiene sustento en las garantías fundamentales del derecho de propiedad y en derecho a realizar cualquier actividad económica lícita que se aseguran al empleador como garantías fundamentales en los numerales 24 y 21 del Artículo 19 de la Constitución Política del Estado.

El derecho a dirigir y organizar el trabajo se denomina tradicionalmente "poder de dirección”, y otorga al empleador la facultad de dar órdenes al trabajador en torno al modo, tiempo y lugar en que debe realizar su trabajo, pues a cambio de ello el trabajador recibe una remuneración. Son inherentes al poder de dirección la potestad disciplinaria, que surge ante el incumplimiento por parte del trabajador de las órdenes e instrucciones que el empleador le imparte, y la potestad reglamentaria, con la posibilidad de traducir tales órdenes e instrucciones en reglamentos internos, instructivos y códigos de conducta.

En algunos países se reconoce expresamente este poder de dirección del empleador, como es el caso del Estatuto de los Trabajadores de España, cuyo Artículo 5 establece que el trabajador debe "Cumplir las órdenes e instrucciones del empresario en el ejercicio regular de sus facultades directivas" y el Artículo 20 agrega: "El trabajador estará obligado a realizar el trabajo convenido bajo la dirección del empresario o persona en quien éste delegue". La Ley de Contrato de Trabajo de Argentina reconoce al empleador la facultad de organización de la empresa y la facultad de dirección en sus Artículos 64 y 65, estableciendo que "la facultad de dirección debe ejercerse atendiendo a los fines de la empresa y a las exigencias de la producción sin perjuicio de la preservación y mejora de los derechos personales y patrimoniales del trabajador", conforme reza su Artículo 65.

En Chile, el poder de dirección no aparece definido de manera explícita pero sí encuentra sustento a nivel legal en el Artículo 5 del Código del Trabajo, al expresar que "El ejercicio de las facultades que la ley le reconoce al empleador, tiene como límite el respeto a las garantías constitucionales de los trabajadores ..."; también en el Artículo 12, a propósito del ius variandi del empleador, cuando dispone que "El empleador podrá alterar la naturaleza de los servicios o el sitio o recinto en que ellos deban prestarse .... A partir de estas normas, surge el deber del trabajador de cumplir las órdenes e instrucciones del empleador.

\subsection{ES PARTE DEL CONTENIDO NO PATRIMONIAL DEL CONTRATO DE TRABAJO}

Este contenido clásico del poder de dirección del empleador contiene obligaciones correlativas, puesto que al subordinarse el trabajador al empleador no sólo en términos jurídicos sino también en una dimensión económica y técnica, el trabajador se verá expuesto a sufrir los riesgos inherentes a la actividad laboral, de los cuales no puede por regla general evadirse puesto que tiene el deber de cumplir con el trabajo contratado.

Surge así el deber de protección del empleador, también denominado deber de cuidado, y que nosotros llamaremos "deber de seguridad", que es inherente al contrato de trabajo en su dimensión no patrimonial y tradicionalmente regulado dentro del denominado contenido ético jurídico del contrato de trabajo. 
En general se lo sitúa dentro de un deber más general del empleador que es el de "deber de protección del trabajador", que incumbe a tres ámbitos fundamentales: la protección de su capacidad laboral, la protección de su capacidad económica y la protección integral de su persona (vida, bienestar, dignidad e intimidad ${ }^{10}$. En su acepción más estricta, si el empresario puede dar órdenes en cuanto al tiempo, lugar y modo de la prestación del trabajador, y estas órdenes han de ser obedecidas, puesto que de su incumplimiento puede derivar una sanción, le es exigible como deber procurar que no sean nocivas para el trabajador y que éste resulte indemne tras su cumplimiento ${ }^{11}$.

El deber de seguridad que es parte del deber más general de protección que emana del contrato de trabajo, no sólo integra la naturaleza del contrato sino que se trata de un deber esencial y principal del mismo, cuya regulación no puede quedar entregada a la autonomía de las partes porque comprende en general una serie de normas de derecho necesario, que derivan de la esencia de la relación laboral ${ }^{12}$.

Ello explica por qué aun cuando no aparezca regulado en el propio texto del contrato, es un elemento que le pertenece, que es de su naturaleza por aplicación del Artículo 1546 de nuestro Código Civil, en cuya virtud "Los contratos deben ejecutarse de buena $\mathrm{fe}^{13}$, y por consiguiente obligan no sólo a lo que en ellos se expresa, sino a todas las cosas que emanan precisamente de la naturaleza de la obligación, o que por la ley o la costumbre pertenecen a ella”.

\subsection{REgulaCión POSITIVA DEL DEBER DE SEgURIDAD Y LOS CONCEPTOS JURÍDICAMENTE INDETERMINADOS QUE CONTIENE}

El deber de seguridad se encuentra regulado en el Libro II Código del Trabajo chileno que se denomina "De la Protección de los Trabajadores", y concretamente dentro del Título I sobre Normas Generales -artículos 184 a 193 - y del Título III que trata "Del Seguro Social contra Riesgos de Accidentes del Trabajo y Enfermedades Profesionales” -artículos 209 a 211-.

El precepto medular dentro de las normas anotadas es el Artículo 184 del Código del Trabajo, que establece en sus incisos $1^{\circ}$ y $2^{\circ}$ :

"El empleador estará obligado a tomar todas las medidas necesarias para proteger eficazmente la vida y salud de los trabajadores, informando de los posibles riesgos y manteniendo las condiciones adecuadas de higiene y seguridad en las faenas, como también los implementos necesarios para prevenir accidentes y enfermedades profesionales. /Deberá asimismo prestar o garantizar los elementos necesarios para que los trabajadores en caso de accidente o emergencia puedan acceder a una oportuna y adecuada atención médica, hospitalaria y farmacéutica.."

\footnotetext{
10 Garriguez Giménez, Amparo. "La Organización del trabajo en la empresa (II). El deber de protección del empresario", en: Derecho del Trabajo -3a edición-. Navarra, Espańa: Editorial Thomson Aranzadi, 2007, p. 408.

11 Alonso Olea, Manuel; Casas Baamonde, María Emilia. Derecho del Trabajo-26a edición- Madrid, España: Thomson Reuters, 2009 , p. 527.

12 Thayer, William; Novon, Patricio. Manual de Derecho del Trabajo. Tomo II. Santiago, Chile: Editorial Jurídica de Chile, 1980, pp. 318-343.

13 El principio de la buena fe en el cumplimiento del contrato de trabajo es para nosotros el fundamento esencial del contenido no patrimonial del contrato de trabajo. No es posible seguir utilizando conceptos tales como la "fidelidad" y la "obediencia" como correlatos de la subordinación del trabajador, los que se encuentran ampliamente superados por la dogmática comparada y también por los ordenamientos jurídicos con la vigencia de los derechos fundamentales del trabajador en la relación de trabajo.
} 
María Cristina Gajardo Harboe / El Deber de Seguridad

En términos similares se establece este deber de cuidado a la empresa principal y a la empresa usuaria de servicios transitorios, en los Artículos 183-E y 183-AB del Código del Trabajo.

El Artículo 184 del Código del Trabajo contiene algunos conceptos jurídicamente indeterminados, tales como el "eficazmente", las "condiciones adecuadas" y los implementos "necesarios" para prevenir los accidentes y enfermedades profesionales, que en la práctica han sido motivo de intenso debate, a los efectos de establecer la naturaleza de la responsabilidad civil de la que responde el empleador; para unos es estricta, al exigirse un determinado resultado -que no se produzcan accidentes del trabajo- y para otros está basada en la culpa por el tenor expreso del artículo 69 letra b) de la Ley $\mathrm{N}^{\circ} 16.744$.

Lo cierto es que se trata de una "obligación dinámica”, que se condice con el carácter consensual y de tracto sucesivo que tiene el contrato de trabajo, que lo hace permeable a los cambios en la forma de hacer el trabajo, a los avances tecnológicos, al marco regulatorio en que se desenvuelve la actividad del empleador, en fin, a diversas circunstancias del entorno laboral que van determinando un modo especial de trabajo que puede influir en la manera de prevenir los riesgos que ello genera y como consecuencia, en la forma de dar cumplimiento al deber de protección.

Entonces, el empleador debe estar constantemente adaptándose a los requerimientos de seguridad que emanan de su propia actividad, y en este sentido la existencia de conceptos jurídicamente indeterminados a los efectos del deber de seguridad que consagra el Artículo 184 del Código del Trabajo favorece esa adaptación, pues habrá que estar a la situación concreta de riesgo, para saber cuáles medidas son las más eficaces para prevenirla, permitiendo crear condiciones adecuadas de trabajo, y con qué elementos de protección podrá impedirse que tal riesgo afecte la vida o la salud de los trabajadores.

Con esta idea no estamos sosteniendo en ningún caso que el Artículo 184 del Código del Trabajo consagre una obligación de resultado, ya que no nos parece posible que el empleador pueda prever y resolver ex ante y en términos absolutos todos los riesgos que pudieran afectar a sus trabajadores. Esta norma debe ser interpretada y aplicada en su mérito, esto es, atendida la finalidad para la cual fue establecida, que no es otra que la de situar en el empleador el deber de seguridad respecto de los riesgos de su propia actividad, porque es él quien cuenta con las herramientas, los conocimientos y los recursos necesarios para realizar en el ámbito de sus operaciones, una eficaz labor preventiva de riesgos laborales.

De lo anterior se colige que aun cuando estemos ante conceptos jurídicos indeterminados, el deber del empleador no lo es. A ello se refiere con mucho acierto Cayetano Núñez ${ }^{14}$ cuando expresa que "la existencia de un riesgo laboral es, a veces, imposible de evitar. Lo que el contenido esencial exige es que, aun cuando el riesgo exista, sus consecuencias lesivas desaparezcan, algo que hoy día es, desde un punto de vista técnico, casi siempre posible."

En la misma línea de lo expresado se encuentra el Convenio 155 de la OIT, cuando atribuye al empleador deberes de cuidado respecto de los factores de riesgo "que estén bajo su control", es decir, aquellos riesgos inherentes a su actividad y que desde una perspectiva técnica deba conocer para poder impedirlos.

Esta lectura del sentido y alcance del Artículo 184 del Código del Trabajo concilia perfectamente la responsabilidad por la seguridad y salud de los trabajadores que asiste al empleador, con el deber de garante que asiste al Estado en tanto se trata de garantías fundamentales.

14 Núñez González, Cayetano. Marco Normativo Chileno dela Prevención de Riesgos Laborales. Santiago, Chile: Editorial Librotecnia, 2013, p. 36. 
En efecto, existen ámbitos de protección imposibles de atribuir al empleador, como es el caso de las condiciones ambientales y sociales generales -contaminación ambiental, políticas de transporte, educación en prevención de riesgos, por citar algunas-; o bien la determinación de estándares mínimos permitidos para el funcionamiento de ciertas actividades productivas. Estas son tareas que corresponden al Estado, pues acá no se trata de discutir si su rol ha de ser benefactor o subsidiario, sino de amparar, garantizar y promover el derecho a la vida y a la integridad física y síquica de los trabajadores, lo que emana muy claramente del Convenio 155 de la OIT al diferenciarse las responsabilidades del Estado de las del empleador.

Entonces, es tarea del Estado establecer reglas técnicas que permitan dar contenido al deber de seguridad del empleador. Porque para poder atribuirle responsabilidad por el incumplimiento a tales deberes, es supuesto fundamental que este conozca las reglas que lo rigen y pueda así adoptar las normas técnicas establecidas con anterioridad para su actividad. No es tarea fácil y ya lo apunta Cayetano Núñez cuando expresa que "el marco normativo se dilata de un modo inexorable, con una extensión que dificulta su conocimiento especializado. El panorama no presenta un manejo sencillo, porque es ineludible conocer, de un lado qué norma es aplicable en cada caso $\mathrm{y}$, de otro, por el debido respeto al principio de integridad del ordenamiento jurídico, cómo se articulan y relacionan todas ellas." ${ }^{\prime 5}$.

En Chile no existe una ley especial que regule de un modo orgánico los conceptos básicos que dicen relación con la prevención de riesgos en el trabajo, tal como ocurre en otras latitudes ${ }^{16}$; nuestra realidad es la de una gran cantidad de reglamentos, resoluciones, circulares e instrucciones emanadas de las autoridades que fiscalizan hasta ahora esta importante materia.

Contar con un marco legal adecuado en prevención de riesgos laborales permitiría delimitar con mayor claridad la responsabilidad del Estado del deber de seguridad del empleador y también contar con la colaboración de los trabajadores, a través de políticas que promuevan el autocuidado. También se lograría tomar distancia de los mecanismos de protección de daños que provienen del Derecho Civil de Daños según el artículo 69 de la Ley $\mathrm{N}^{\circ} 16.744$, pues con ellos no se promueven los valores que venimos refiriendo: la seguridad y salud en el trabajo.

En suma, la obligación de seguridad emana de la naturaleza del contrato de trabajo siendo parte de su contenido no patrimonial, lo que no libera al Estado de su deber de establecer reglas obligatorias y un marco jurídico adecuado en razón de su deber de garante de los derechos fundamentales consagrados en el Artículo 1 de la Constitución Política del Estado, esto es, el derecho a la vida y salud de los trabajadores.

\section{NATURALEZA JURÍDICA DEL DEBER DE SEGURIDAD DEL EMPLEADOR}

Existen distintas posiciones doctrinales en torno a la naturaleza jurídica del deber de seguridad del empleador, cuya suscripción produce consecuencias relevantes.

\footnotetext{
$15 \quad$ Ibid, p. 55.

16 La Ley 31/1995 sobre Prevención de Riesgos Laborales regula en España en un solo cuerpo normativo las reglas básicas de promoción y cuidado de la seguridad y salud en el trabajo, que son obligatorias para las entidades empleadoras del sector privado y también para el sector público.
} 
En efecto, si se considera que es de naturaleza contractual habrá repercusiones en la sede jurisdiccional que conoce de los asuntos en que se discuta el incumplimiento de este deber, debiendo conocer el tribunal laboral en conformidad al artículo 420 del Código del Trabajo, con la consecuente celeridad que el proceso laboral cuenta actualmente; la valoración de la prueba se hará conforme a las reglas de la sana crítica según establece el artículo 456 del mismo código; la culpa que se atribuye al empleador en los daños derivados del accidente se presumirá porque así lo señala el artículo 1547 del Código Civil, y el plazo de prescripción de la acción para demandar será de cinco años, por aplicación del artículo 2515 del Código Civil o como se considera más recientemente por algunos con fundamento en el artículo 79 de la Ley $\mathrm{N}^{\circ} 16.744$.

Si se estima que esta es una obligación de fuente legal -con base en el artículo 184 del Código del Trabajo- la sola ocurrencia de un accidente del trabajo o enfermedad profesional constituye un incumplimiento, convirtiendo al deber de seguridad en una obligación de resultado porque se está en un ámbito infraccional, siendo irrelevante si existió o no culpa de la entidad empleadora en el acaecimiento del hecho. La única excepción posible a esta regla es probar que el accidente se hubiera producido de igual modo a pesar de los cuidados observados por el empleador.

\subsection{Naturaleza CONTRACTUAL DEL DEber DE SEGURidad}

En la dogmática laboral clásica se considera como un deber que encuentra su origen en el contrato de trabajo y por tanto esa es su naturaleza: contractual.

Así, Manuel Alonso Olea y María Emilia Casas Baamonde afirman que este deber no tiene un fundamento unívoco, sino una pluralidad de fundamentos jurídicos, todos los cuales reposan en última instancia sobre el contrato de trabajo ${ }^{17}$.

William Thayer y Patricio Novoa sostienen que el contenido, forma y extensión del deber de protección están reglados por la autoridad mediante normas de orden público, no obstante reconocerse su origen contractual, lo que explican por la naturaleza compleja de este deber, obligación contractual pero regulada por normas de derecho necesario emanadas de la autoridad, que ha emergido como la respuesta que ha debido dar el Estado moderno al gran auge del maquinismo y la revolución industrial ${ }^{18}$.

Por su parte, Irene Rojas ${ }^{19}$ trata el deber de seguridad bajo la denominación de deber de seguridad y salud en el trabajo dentro del contenido ético-jurídico del contrato de trabajo. Expresa que:

"la doctrina tradicional otorga a este contenido fundamentos más bien débiles, en circunstancias de que los derechos del trabajador tienen base jurídica segura y fuerte. Primero, protección de la persona del trabajador, por una parte a la dignidad respecto a los Derechos Humanos. Segundo, el deber de seguridad y salud en el trabajo. Tercero, protección de la capacidad profesional del trabajador. Protección a la maternidad".

Nos parece que no admite discusión el carácter contractual del deber de seguridad del empleador, en tanto existe un contrato de trabajo que lo vincula con el trabajador y a partir de él

Alonso Olea, Manuel; Casas Baamonde, María Emilia, op. cit. (n. 11), p. 528.

Thayer, William; Novoa, Patricio, op. cit. (n. 11), pp. 327-328.

Rojas Miño, Irene. Manual de Derecho del Trabajo. Santiago, Chile: Editorial Lexis-Nexis, 2004, pp. 173-174. 
surgen prestaciones mutuas que es preciso satisfacer, una de las cuales es el deber que referimos, que según sostuvimos antes es una contrapartida al poder de dirección que detenta el empleador.

Enseguida se fundamenta en el artículo 1546 del Código Civil, a propósito de la buena fe con que deben ejecutarse los contratos.

Muestra de ello es también el artículo 420 letra f) del Código del Trabajo, cuando entrega al conocimiento de los tribunales laborales "los juicios en que se pretenda hacer efectiva la responsabilidad del empleador derivada de accidentes del trabajo o enfermedades profesionales, con excepción de la responsabilidad extracontractual a la cual le será aplicable lo dispuesto por el artículo 69 de la Ley N¹6.744", de lo que se sigue que cuando la responsabilidad en el accidente o enfermedad laboral no radica en el empleador, hay que estarse al estatuto de responsabilidad extracontractual.

En fin, el carácter contractual de este deber no muta en deber legal tan solo por existir normas positivas que lo regulen, lo que se explica en atención a la importancia de los bienes jurídicos que ampara y en la necesidad de contar con criterios técnicos que lo materialicen.

Ejemplos del reconocimiento del carácter contractual del deber de seguridad:

- $\quad$ "Luis Enrique Ríos Poblete Con Constructora Senarco S.A. e Inmobiliaria Titanium S.A.", Primer Juzgado del Trabajo de Santiago, Rol O-786-2011, 16 de junio de 2011: En cuanto a la responsabilidad que le compete al empleador por accidente de trabajo, de acuerdo a lo sostenido por la doctrina y jurisprudencia laboral si es el mismo trabajador quien la reclama, es de índole contractual, pues dice relación con el incumplimiento al deber de seguridad, consagrado en el artículo 184 del Código del Trabajo, obligación que comprende la protección y cuidado de la vida y salud del trabajador y que se encuentra incorporado al contrato de trabajo, como parte de su contenido ético jurídico.

- "Giovanni Alexis Díaz Mondaca con Empresa Constructora Bravo e Izquierdo Limitada”, Segundo Juzgado del Trabajo de Santiago, Rol O-3314-2011, 23 de enero de 2012: No obedece la responsabilidad de que se trata a un estatuto estricto que prescinde de las actuaciones de las partes, especialmente del contratante deudor de seguridad, como lo plantea el demandante, sino de la consagración legal de un deber contractual que se erige sobre un estándar de diligencia y eficiencia en relación a las faenas y tareas individuales de los destinatarios de él, vinculado con diversos aspectos que abarcan desde la capacitación de los trabajadores y su equipamiento, hasta la adecuación de los espacios físicos y el proceso productivo.

\subsection{NATURAleza LEGAl O MIXTA DEL DEBER DE SEGURIDAD}

Desde la dogmática civilista se ha venido sosteniendo que existe además del carácter contractual un componente legal en la obligación de seguridad del empleador.

Así, para Jorge Baraona ${ }^{20}$ no existen dudas de que se trata de deberes contractuales, pues ellos nacen como consecuencia de que una persona se incorpora al trabajo como efecto de la celebración de un contrato de trabajo; pero la cuestión es determinar si son únicamente contractuales. Refiere el principio de buena fe contractual del cual podrían inferirse los deberes de seguridad del empleador incluso al margen de artículo 184 del Código del Trabajo. Declara que dado el carácter contractual que reconocemos al principio de buena fe, es obvio que su fuerza obligatoria

20 Baraona González, Jorge. "La culpa de la víctima en los accidentes del trabajo: dogmática y jurisprudencia chilenas", en: Cuadernos de Extensión Jurídica, n²0. Santiago, Chile: Universidad de Los Andes, 2011, pp. 147-181. 
María Cristina Gajardo Harboe / El Deber de Seguridad

no alcanza únicamente al empleador, sino que también compromete la actuación de los propios trabajadores. Sin embargo, sostiene que el deber de seguridad no encuentra su justificación última en el acuerdo de voluntades que dio nacimiento al contrato de trabajo, sino que ha de buscarse un fundamento superior en el deber general de respetar la vida y seguridad de los demás, lo que viene impuesto por la ley.

Concluye que bajo la mirada conjunta de la Constitución, el Código Civil y el Código del Trabajo, los deberes de seguridad en el trabajo tienen una doble naturaleza: contractuales y legales, lo que produce un concurso de normas que dan lugar a acciones semejantes pero no idénticas en cuanto al estatuto jurídico por las que se rigen.

Por su parte, Enrique Barros ${ }^{21}$ sostiene que desde un punto de vista jurídico el deber de cuidado del empleador corresponde a una obligación de seguridad que tiene por objeto la integridad física y psíquica del trabajador, la que no es implícita -como ocurre usualmente en materia contractual- sino que está expresamente consignada en el artículo 184 del Código del Trabajo. Por aplicación de las reglas generales del derecho común, el empleador responde de la "culpa leve", en los términos del artículo 1547 del Código Civil, con un estándar de diligencia que se corresponde con el de un empresario prudente y diligente que debe adoptar las prevenciones en consideración a la entidad de los bienes jurídicos comprometidos. Pareciera que opta por la naturaleza contractual de la obligación de seguridad, en tanto la relación entre el trabajador y el empleador tiene su fuente en el contrato de trabajo. Sin embargo, destaca que las obligaciones relevantes del empleador están definidas por normas de orden público, que le imponen "deberes legales" de cuidado. ${ }^{22}$

Ejemplo del reconocimiento del carácter legal del deber de seguridad:

- $\quad$ "María Llanca Gajardo y otros con Alejandra Uribe Cuevas", Rol 676-2010, Corte de Apelaciones de Concepción, 30 de noviembre de 2010: el deber de protección y seguridad impuesto al empleador en el Artículo 184 del Código del Trabajo tiene el carácter de obligación legal, de manera que debe ser el empleador quien deba acreditar que hizo efectivas todas las medidas de seguridad para eximirse de la responsabilidad que el legislador le atribuye. En razón de lo establecido precedentemente, la culpa del empleador demandado en esta causa se ha traducido en la inobservancia de su deber legal de otorgar seguridad efectiva a su trabajador, lo que motivó el accidente del trabajo y la muerte del trabajador, existiendo la relación de causa a efecto entre el hecho dańoso y su resultado.

No compartimos la naturaleza mixta del deber de seguridad, postura que importada del Derecho Civil, no reconoce los orígenes de la protección de los riesgos laborales dentro del Derecho de la Seguridad Social. Ya lo reconoce Irene Rojas cuando refiere a propósito de la vigencia de los derechos fundamentales al interior de la relación laboral, que nos enfrentamos a una de las tareas más complejas del Derecho del Trabajo: el reconocimiento de estos derechos fundamentales hace necesaria la revisión de las bases dogmáticas del contrato de trabajo, las que ancladas en el Derecho Civil necesitan su adecuación a las exigencias de la plena vigencia de los derechos fundamentales. ${ }^{23}$

\footnotetext{
21 Barros Bourie, Enrique. Tratado de Responsabilidad Extracontractual. Santiago, Chile: Editorial Jurídica de Chile, 2006, pp.704-706.

$22 \quad$ Ibid, p. 701

23 Rojas Miño, Irene, op. cit. (n. 19), p. 174.
} 
La huida del seguro privado imperante bajo el Código del Trabajo de 1931, en que se consagraba la responsabilidad directa -y estricta- del empleador en los riesgos laborales de sus trabajadores, dejó paso a un sistema de protección en el marco del Derecho de la Seguridad Social, con la Ley $\mathrm{N}^{\circ} 16.744$ en el año 1968, cuyo artículo 69 literal b) establece con toda claridad una acción en favor de la víctima de un accidente del trabajo o enfermedad profesional y de sus herederos, para demandar "las otras indemnizaciones a que tengan derecho, con arreglo a las prescripciones del derecho común, incluso el daño moral".

Esto significó que de manera explícita quedó a salvo la acción indemnizatoria civil que estaba presente en el artículo 260 del Código del Trabajo de 1931, recogiendo el "principio de complementariedad de las indemnizaciones" - la de la seguridad social y la civil-, cuestión que de ninguna forma puede significar, como algunos han creído entender, que existe una especie de responsabilidad legal en torno a esta materia o que el deber de seguridad tiene fuente legal, más aun cuando el actual artículo 184 del Código del Trabajo tenía a esa fecha un tenor prácticamente idéntico al actual ${ }^{24}$.

No puede olvidarse que el deber de seguridad es un elemento de la naturaleza del contrato de trabajo, esto es, que aun cuando las partes no se refieran a él de manera explícita en el documento en que consten las cláusulas del contrato de trabajo, de todas formas se entiende que le pertenece.

Los especialistas en Derecho Civil, acostumbrados a la formalidad y las solemnidades propias de su disciplina, han visto en este deber una obligación legal, tan solo porque la ley se refiere a ella, olvidando considerar que el contrato de trabajo es consensual, de tracto sucesivo y por tanto dinámico, que contiene diversas obligaciones que van más allá de los deberes de prestar servicios y pagar una remuneración, lo que es extraordinario porque lo humaniza. Y no obstante tratarse de un contrato dirigido, regulado por normas de orden público, estas características por sí solas no pueden determinar la existencia de un régimen de obligaciones de fuente legal.

\section{3 ¿Es UNA ObLIGACIÓN DE MEDIOS O DE RESUlTAdo?}

La redacción del artículo 184 del Código del Trabajo parece contribuir a interpretaciones equívocas en torno a si la obligación de seguridad del empleador es, a los efectos de la responsabilidad civil, un deber de medios o un deber de resultado.

Siguiendo a Enrique Barros, a diferencia del régimen de seguro de accidentes y enfermedades, la responsabilidad civil tiene por antecedente la culpa del empleador y no una obligación de garantía que dé lugar a responsabilidad por el solo hecho de producirse el daño en la esfera de cuidado del empleador, lo que funcionalmente equivale a una responsabilidad estricta contractual; de hecho, esta función de garantía es cumplida por el seguro de accidentes del trabajo, en su calidad de seguro de daños ocurridos con ocasión de la relación laboral, y cuyas prestaciones se devengan con independencia de la conducta del empleador. Agrega que las obligaciones de seguridad, a diferencia de las obligaciones de garantía, no tienen por objeto asegurar que el acreedor quedará

\footnotetext{
24 Artículo 244 del Código del Trabajo de 1931: "El patrón o empresario está obligado a tomar todas las medidas necesarias para proteger eficazmente la vida y salud de sus obreros y empleados. / Para este efecto deberá proceder, dentro del plazo que fije la Inspección General del Trabajo y de acuerdo con las disposiciones que determine el Reglamento, a introducir, por su cuenta, todas aquellas medidas de higiene y seguridad en los locales del trabajo y de salubridad convenientes a las viviendas de las empresas, industrias y faenas en general./ Deberá, asimismo, disponer de los elementos de protección necesarios para prestar, en caso de accidente de sus obreros o empleados, oportuna y adecuada atención médica, farmacéutica y hospitalaria”.
} 
María Cristina Gajardo Harboe / El Deber de Seguridad

indemne de todo daño, sino establecen un deber de cuidado que debe ser apreciado según las circunstancias ${ }^{25}$.

La jurisprudencia mayoritaria pareciera inclinarse por calificar esta obligación de seguridad como una obligación de medios. Veamos algunos ejemplos:

- $\quad$ "Morales Guzmán, Danny contra Automática y Regulación S.A.”, Rol N³495-2010, Corte Suprema, 18 de octubre de 2010: la responsabilidad civil del contratante a quien la ley asigna la aludida carga, se sustenta claramente en la culpa del mismo en relación a la esfera de cuidado de la seguridad e integridad física y síquica del trabajador, cuya observancia debe ser analizada y declarada de acuerdo a las circunstancias de cada caso, por cuanto la severidad de las expresiones que contiene el precepto, a saber, "todas las medidas" o "eficazmente", en ningún caso traducen una obligación de garantía que asegure la indemnidad frente a todo dańo, como sí lo hace el régimen de seguro social de accidentes del trabajo y enfermedades profesionales contenido en la ley $\mathrm{N}^{\circ} 16.744$.

- $\quad$ "Álvarez Astete, Erwin contra Sociedad Comercial y Constructora Lomas Limitada”, Rol 1582010, Corte de Apelaciones de Concepción, 27 de septiembre de 2010: para que pueda resultar aplicable la ley No 16.744 es esencial que se acredite en la especie la existencia de un accidente del trabajo o enfermedad profesional y aun en este caso, debe considerarse que no todo hecho acontecido en el lugar de trabajo implica la existencia de responsabilidad por parte del empleador, pues no se ha contemplado una responsabilidad objetiva en tal sentido; por el contrario, el factor de imputación seguido en nuestra legislación es de carácter subjetivo y descansa en la existencia de culpa o dolo por parte de la entidad empleadora, como lo indica textualmente el artículo 69 de la ley No 16.744. Por otra parte, el artículo 184 del Código del Trabajo impone al empleador la obligación de cuidar eficazmente la vida y salud de sus trabajadores, obligación que ha sido calificada como una obligación de medios, lo que lleva a concluir que el empleador no ha contraído la obligación de garantizar la no concurrencia absoluta de accidentes en el lugar de trabajo, sino de procurar por todos los medios posibles que éstos sean evitados.

Ya señalamos que el deber de seguridad a nivel legal se regula fundamentalmente en el Artículo 184 del Código del Trabajo, con conceptos jurídicamente indeterminados que pueden confundir al intérprete, en cuanto se exige protección "eficaz", condiciones "adecuadas" e implementos de seguridad "necesarios" para prevenir los accidentes del trabajo y enfermedades profesionales. Sin embargo, hemos también precisado que estos conceptos han de ser entendidos en función de la finalidad para la cual fueron establecidos, esto es, que el empleador se ocupe de los riesgos que genera su actividad, lo que se traduce en el cumplimiento de las normas técnicas que lo rigen en materia de prevención de riesgos laborales.

De esta forma, no es correcta la afirmación de que el Artículo 184 del Código del Trabajo consagre una obligación de resultado, más aun con el claro tenor del artículo 69 literal b) de la Ley $\mathrm{N}^{\circ} 16.744$, que permite accionar en contra del empleador por los daños que genere un accidente del trabajo o enfermedad profesional conforme a un estatuto de responsabilidad por culpa.

Barros Bourie, Enrique, op.cit. (n. 21), pp. 704-705. 


\section{EL DEBER DE SEGURIDAD DEL TRABAJADOR}

El deber de seguridad también incumbe a los trabajadores en tanto forman parte de la relación de trabajo, pero en una dimensión distinta a la del empleador. Es así pues son ellos los que realizan las labores que pueden llevarlos a sufrir infortunios laborales y en consecuencia deben observar las conductas que estén a su alcance, sea por su conocimiento de los riesgos que atañen a su actividad laborativa específica o simplemente por las máximas de experiencia, atendiendo al cuidado que cualquier persona debe tener en los actos de la vida diaria.

El Convenio 155 de la OIT se refiere a este deber en su Artículo 19, al consignar que los trabajadores y sus representantes deben cooperar al cumplimiento de las obligaciones que incumben al empleador en el ámbito de la seguridad e higiene en del trabajo.

La legislación de la Unión Europea así lo ha entendido también, por ejemplo a través de la Directiva 89/391/CEE de 12 de junio de 1989 relativa a la Aplicación de Medidas para Promover la Mejora de la Seguridad y de la Salud de los Trabajadores en el Trabajo, en cuya sección III dedica un capítulo a las obligaciones de los trabajadores, y en particular el Artículo 13, que por su importancia transcribimos:

"1. Competerá a cada trabajador velar, según sus posibilidades, por su seguridad y su salud, así como por las de las demás personas afectadas, a causa de sus actos u omisiones en el trabajo, de conformidad con su formación y las instrucciones de su empresario.

2. A fin de realizar dichos objetivos, los trabajadores con arreglo a su formación y a las instrucciones de su empresario, deberán en particular:

a) utilizar correctamente las máquinas, aparatos, herramientas, sustancias peligrosas, equipos de transporte y otros medios;

b) utilizar correctamente el equipo de protección individual puesto a su disposición y, después de su utilización, colocarlo en su sitio;

c) no poner fuera de funcionamiento, ni cambiar o desplazar arbitrariamente los correspondientes dispositivos de seguridad de las máquinas, aparatos, herramientas, instalaciones y edificios, y utilizar tales dispositivos de seguridad correctamente;

d) indicar inmediatamente al empresario y / o a los trabajadores que tengan una función específica en materia de protección de la seguridad y de la salud de los trabajadores, toda situación laboral que, por un motivo razonable, consideren que entraña un peligro grave e inminente para la seguridad y la salud, así como todo defecto que se haya comprobado en los sistemas de protección;

e) contribuir, de conformidad con los usos nacionales y durante el tiempo que fuere necesario, junto con el empresario y / o los trabajadores que tengan una función específica en materia de protección de la seguridad y de la salud de los trabajadores, a que puedan cumplirse todas las tareas o exigencias impuestas por la autoridad competente con el fin de proteger la seguridad y la salud de los trabajadores en el trabajo;

f) contribuir, de conformidad con los usos nacionales y durante el tiempo que fuese necesario, junto con el empresario y / o los trabajadores que tengan una función específica en materia de protección de la seguridad y de la salud de los trabajadores, a que el empresario 
María Cristina Gajardo Harboe / El Deber de Seguridad

pueda garantizar que el medio y las condiciones de trabajo sean seguros y no presenten riesgos para la seguridad y la salud dentro de su ámbito de actividad”.

Los países europeos han recogido con distintas variantes estos lineamientos, como es el caso de España con la Ley N³1/95 sobre Prevención de Riesgos Laborales; en los Artículos 18 y 19 se regula con detalle la participación de los trabajadores en la tarea preventiva y su formación profesional.

En Chile no tenemos un desarrollo normativo a este nivel. Existe sí el DS Nº40 de 1969, del MTPS, que contiene el Reglamento de Prevención de Riesgos Profesionales, en donde a propósito del contenido del Reglamento Interno de Higiene y Seguridad se indica que en el capítulo de obligaciones este instrumento debe comprender normas sobre el uso correcto y cuidado de los elementos o dispositivos de protección personal, la obligación de dar cuenta de síntomas de enfermedad profesional o accidentes, cooperar en la investigación de accidentes, comunicar desperfectos que afecten la seguridad personal, acatar normas internas sobre métodos de trabajo u operaciones o medidas de higiene y seguridad, participación en prevención de riesgos de capataces, jefes de cuadrillas, supervisores, jefes de turno o sección y otras personas responsables. También se establece la enumeración de actos o acciones no permitidos por envolver riesgos, como trabajar bajo influencia del alcohol, retirar o dejar inoperantes elementos o dispositivos de seguridad e higiene instalados por la empresa, destruir o deteriorar material de propaganda visual o de otro tipo destinado a la promoción de la prevención de riesgos, operar o intervenir maquinarias o equipo sin autorización, desentenderse de normas o instrucciones de ejecución o de higiene y seguridad impartidas para un trabajo dado -Artículos 18 y 19-.

Estimamos que estas disposiciones son insuficientes para regular lo que venimos explicando, esto es, el deber de protección entendido desde la perspectiva de los trabajadores, puesto que pueden estar o no en los reglamentos internos de los empleadores, siendo estos últimos quienes definen su contenido, que no siempre será preciso y determinado. Además, quedan fuera de estas reglas los trabajadores independientes, quienes también realizan actividades que pueden significar riesgos para su seguridad y salud en el trabajo.

En un sentido promocional, este deber de seguridad debiera regularse a través de normas de rango legal que contemplen las obligaciones correlativas de los trabajadores en forma precisa, independiente del estatuto por el que se rijan, de manera tal que se proteja a los trabajadores dependientes del sector privado, sea que estos realicen su labor en el recinto del empleador o en un lugar libremente elegido por ellos; a los funcionarios públicos; a los funcionarios municipales y a los trabajadores independientes.

Con todo, y aun cuando Chile no cuenta con normas de rango legal que regulen el deber de seguridad de los trabajadores, nuestros tribunales se han referido innominadamente a ello al conocer de asuntos en que se discutía la responsabilidad civil del empleador:

- $\quad$ "Barría Carmona, María Adelita con González Kettler, Pablo Alberto", Rol 2975-2006, Corte Suprema, 28 de agosto de 2007: se expresa que el deber de vigilancia y cuidado consagrado en el artículo 184 del Código del Trabajo ha sido llevado al extremo, si se tiene en cuenta que a los trabajadores les estaba expresamente prohibido subirse a este tipo de máquinas motorizadas que realizaban maniobras o trabajos dentro del establecimiento, lo que constaba en el Reglamento de Higiene y Seguridad, que fue recibido por la víctima. Se ha aplicado incorrectamente dicho precepto por cuanto las medidas que requiere del empleador para proteger la 
vida y la salud de los trabajadores aparecen adoptadas por el demandado, no pudiendo exigirse medidas que contemplan e impidan conductas que van contra la normal ocurrencia de los sucesos, como lo constituye el transportarse en una pisadera de un tractor; los acontecimientos ocurridos, sólo son imputables a quien, contraviniendo órdenes expresas, incurre en un comportamiento que además es contrario a lo normal.

- $\quad$ "Orellana Cataldo Cesar David con Hormigones Transex Ltda.”, Rol 7739-2011, Corte Suprema, 6 de julio de 2012: la obligación del Artículo 184 del Código del Trabajo debe entenderse en el marco del desarrollo de la labor para la cual fue contratado el trabajador dentro de la racionalidad necesaria a las respectivas funciones. En el caso, ha quedado asentado que el dependiente el día del accidente de motu proprio decidió atravesar por la pasarela improvisada por los trabajadores de la cuadrilla que trabajaban el hormigón en la losa, existiendo otras alternativas seguras para trasladarse entre los departamentos, es decir, actuó con negligencia en el desempeño de sus tareas, sin que, en ese aspecto, pudiera exigirse al empleador una conducta determinada.

- $\quad$ "Administradora de Supermercados Hiper Ltda. con Pasmiño Palma Carlos", Rol 1559-2013, Corte de Apelaciones de Santiago, 24 de abril de 2014: en voto de minoría del Ministro Juan Cristóbal Mera se indica que la sentencia ha establecido los hechos, pudiendo concluirse que el accidente que provocó la lesión del demandante se debió a que éste cargaba una caja que contenía carne, dejando en la parte superior de dicho bulto un cuchillo que se deslizó, cayó y le produjo un corte en su mano izquierda. Si esos son los hechos, ninguna responsabilidad podrá tener la empresa demandada, desde que el resultado dañoso se ha debido a la negligencia del propio trabajador y no a una infracción al deber de seguridad que tiene el empleador respecto de sus trabajadores contemplada en el artículo 184 del Código del Trabajo. Está probado que el trabajador tenía los elementos de seguridad y el entrenamiento necesario para efectuar su labor de maestro carnicero, y en realidad no se necesita entrenamiento alguno para saber que si se carga una caja y se deja en su parte superior un cuchillo afilado éste puede deslizarse, caer y provocar una herida más o menos grave. Se trata de exigir el propio cuidado razonable que cualquier persona normal se prodigaría.

\section{A MODO DE CONCLUSIÓN}

Hemos referido en estas líneas las obligaciones que en materia de seguridad y salud en el trabajo tienen el empleador, el trabajador y el Estado, a partir de las herramientas disponibles en el ordenamiento jurídico vigente.

Sin embargo, estimamos que se necesita de manera urgente un marco legal y reglamentario que, desde el Derecho del Trabajo y de la Seguridad Social, permita avanzar hacia un derecho de la prevención de riesgos laborales, desde el cual se promuevan como valores fundamentales el derecho a la vida y a la salud de los trabajadores. 


\section{BIBLIOGRAFÍA}

Alonso Olea, Manuel; Casas Baamonde, María Emilia. Derecho del Trabajo-26a edición- Madrid, España: Thomson Reuters, 2009.

Baraona González, Jorge. "La culpa de la víctima en los accidentes del trabajo: dogmática y jurisprudencia chilenas", en: Cuadernos de Extensión Jurídica, n²0. Santiago, Chile: Universidad de Los Andes, 2011.

Barros Bourie, Enrique. Tratado de Responsabilidad Extracontractual. Santiago, Chile: Editorial Jurídica de Chile, 2006.

Garriguez Giménez, Amparo. "La Organización del trabajo en la empresa (II). El deber de protección del empresario”, en: Derecho del Trabajo -3a edición-. Navarra, Espańa: Editorial Thomson Aranzadi, 2007.

Núñez González, Cayetano. Marco Normativo Chileno dela Prevención de Riesgos Laborales. Santiago, Chile: Editorial Librotecnia, 2013.

Rojas Miño, Irene. Manual de Derecho del Trabajo. Santiago, Chile: Editorial Lexis-Nexis, 2004.

Silva Bascunán, Alejandro. Tratado de Derecho Constitucional. Tomo XIII. Santiago, Chile: Editorial Jurídica de Chile, 2010.

Thayer, William; Novoa, Patricio. Manual de Derecho del Trabajo. Tomo II. Santiago, Chile: Editorial Jurídica de Chile, 1980 .

Verdugo Marinkoovic, Mario. “Acerca de los Derechos Fundamentales y sus Garantías”, en: Derechos Fundamentales. Santiago, Chile: Editorial Jurídica de Chile, 2012. 